\title{
Análise estratigráfica e tafonômica da sequência Neopraguiana - Eoemsiana do setor nordeste do sítio urbano de Ponta Grossa, Paraná, Brasil
}

\author{
Stratigraphic and taphonomic analysis of Neopragian - \\ Eoemsian sequence from northeast sector of Ponta Grossa, \\ Paraná, Brazil
}

\author{
Análisis estratigráfico y tafonómico de la secuencia \\ Neopraguiana -Eoemsiana del sector nordeste del sitio urbano \\ de Ponta Grossa, Paraná, Brasil
}

Elvio Pinto Bosetti

elvio.bosetti@pq.cnpq.br

Universidade Estadual de Ponta Grossa

Rodrigo Scalise Horodyski rodrigo.geo@gmail.com Universidade Federal do Rio Grande do Sul

Willian Mikio Kurita Matsumura williammatsumura@gmail.com Universidade Federal do Rio Grande do Sul

Lucinei José Myszynski Junior lucineigeo@gmail.com Universidade Estadual de Ponta Grossa

Daniel Sedorko dsedorko@gmail.com Universidade Estadual de Ponta Grossa

\begin{abstract}
Resumo: $\mathrm{O}$ estudo tafonômico desenvolvido nas seções estratigráficas de superfície denominadas Cescage e Curva II forneceu dados que, em conjunto com as demais seções correlacionadas (Francelina, Campus UEPG, Curva I e Franco da Rocha), foram suficientes para diagnosticar ambientes de shoreface a offshore em toda a Sequência B da Formação Ponta Grossa. Foram identificadas 4 associações tafonômicas (AT) que se distinguem pelas diferentes assinaturas tafonômicas, como graus de autoctonia/ aloctonia, diacronismo e processos sedimentares. Destaca-se aqui que, possivelmente, o registro tafonômico de associações fósseis influenciadas por eventos de tempestade são consideradas como condição subprimária. Essas novas interpretações auxiliam nos estudos paleoambientais e paleoautoecológicos, além da possibilidade de estimar
\end{abstract}


a magnitude dos eventos de tempestade que atuaram na formação das concentrações fossilíferas aqui estudadas.

Palavras-chave. Tafonomia. Formação Ponta Grossa. Devoniano. Bacia do Paraná. Província Malvinocáfrica.

\begin{abstract}
New interpretations of paleoenvironmental sedimentary strata regarding Sequence B of Ponta Grossa Formation (Lower Devonian of the Paraná Basin) are presented here. The taphonomic study developed in the stratigraphic surface sections provided data which, together with other sections correlated, were sufficient to diagnose shoreface to offshore environments throughout the sequence. In these environments were identified four taphonomic associations that have distinguished due to different taphonomic signatures, such as degree of autochthony/allochtony, diachronism and sedimentary processes. As a result it was concluded that possibly the record taphonomic fauna Malvinokaffric in Ponta Grossa Formation can be more allochthonous than has hitherto been interpreted.
\end{abstract}

Keywords: Taphonomy. Ponta Grossa Formation. Devonian. Paraná Basin. Malvinokaffric Realm.

Resumen: Se presenta aquí una nueva interpretación paleambiental de la secuencia B de la Formación Ponta Grossa (Devónico Inferior), Cuenca Paraná. El estudio tafonómico llevado a cabo en secciones estratigráficas de superficie proporcionó datos que, junto con otras secciones correlacionadas, permiten diagnosticar ambientes de shoreface a offshore en toda la secuencia. En estos ambientes se analizaron rasgos tafonómicos de los fósiles presentes tales como, el grado de autoctonía / aloctonía, diacronismo y procesos sedimentarios, los cuales permitieron caracterizar cuatro asociaciones tafonómicas. Se concluye que posiblemente el registro tafonómico de la fauna Malvinocáfrica en la Formación Ponta Grossa sería más alóctono de lo que hasta ahora fue interpretado.

Palabras clave. Tafonomía. Formación Ponta Grossa. Devónico. Cuenca Paraná. Provincia Malvinocáfrica.

\title{
INTRODUÇÃO
}

A região de Ponta Grossa, Paraná, destaca-se no cenário da Paleontologia brasileira por apresentar excelentes afloramentos representantes do Período Devoniano e tem sido objeto de trabalho de diversos autores em mais de um século e meio de pesquisas, sendo o trabalho de Clarke (1913) o marco inicial das pesquisas paleontológicas. No entanto, devido ao constante crescimento do sítio urbano, muitas localidades fossilíferas clássicas jazem hoje sob a pavimentação da cidade (ver GRAHN et al., neste volume). Porém, os afloramentos localizados em cortes de estradas de ferro encontram-se ainda em razoável estado 
de conservação. O presente trabalho aborda as seguintes seções estratigráficas: Francelina, Campus UEPG, Curva I e II, Franco da Rocha e Cescage, todos localizados no setor nordeste do perímetro urbano de Ponta Grossa (Zonas 1, 2 e 3 de CRUZ, 2008) e são representantes de ambientes marinhos que datam do Neopraguiano ao Eoemsiano (Sequência B, Formação Ponta Grossa sensu GRAHN et al., 2013). Com exceção dos afloramentos Curva II e Cescage, os demais já foram objetos de estudos de ordem tafonômica e estratigráfica (ver BOSETTI et al., 2009). Por esse motivo, um maior detalhamento tafonômico é conferido a essas duas áreas de ocorrência fossilífera. Na Formação Ponta Grossa, diversos autores trabalharam na região sob variados aspectos da Paleontologia, por exemplo, a distribuição estratigráfica da paleofauna (POPP \& BORCELLOS-POPP, 1986), a sistemática dos lingulídeos (BOSETTI, 1989), a sistemática dos moluscos (KOTZIAN, 1995) e a sistemática dos equinodermos (SCHEFFLER, 2010), evidenciando a excelente representação fossilífera dessa unidade. Os afloramentos Curva II e Cescage, inclusos na Formação Ponta Grossa, até o presente momento, nunca foram abordados sob o ponto de vista da Tafonomia. Todos os seis afloramentos aqui estudados em conjunto revestem-se de grande importância estratigráfica e paleontológica do Devoniano Inferior nessa região.

\section{MATERIAL E MÉTODOS}

Para os trabalhos de coleta do material fóssil nas seções estudadas, utilizou-se o Protocolo tafonômico/paleoautoecológico de Simões \& Ghilardi (2000), sendo desenvolvidos ainda alguns procedimentos característicos para coleta sistemática dos bioclastos (cf. BOSETTI, 2004; BOSETTI et al., 2009), como se segue abaixo:

a) delimitação do escopo de estudo;

b) intervalo estratigráfico e as fácies sedimentares envolvidas;

c) atividades de coleta, localização e reconhecimento no campo;

d) identificação dos tipos de concentrações fossilíferas.

Com o objetivo de se obter o máximo de informações possíveis, foi utilizada uma metodologia de coleta de alta resolução (com dados adquiridos centímetro a centímetro, dentro de quadrículas previamente demarcadas), que se constitui em um processo de varredura dos fósseis. Para isso, foram necessários alguns procedimentos específicos conforme discriminados abaixo:

1- Coleta em quadrículas: são demarcadas quadrículas medindo no mínimo $3 \mathrm{~m}$ de base por $2 \mathrm{~m}$ de altura. Em alguns casos (quando a exposição de rocha permite), aprofunda-se $1 \mathrm{~m}$, procurando uma leitura em três dimensões;

2 - As quadrículas são demarcadas evitando-se proximidade de dobramentos, falhamentos ou diques (pois isso poderia interferir na orientação original dos bioclastos).

O material paleontológico encontra-se depositado no Laboratório de Estratigrafia e Paleontologia do Departamento de Geociências da Universidade Estadual de Ponta Grossa, sob a sigla DEGEO/MPI - 2159 a 2519, além de 58 amostras em processo de catalogação, totalizando 418 amostras. 
Para a correlação estratigráfica das seções estudadas, foram utilizadas as características litológicas, paleontológicas e tafonômicas a fim de demonstrar a correspondência em caráter e posição estratigráfica local-regional. A paleoecologia de cada grupo foi baseada conforme segue: braquiópodes (WILLIAMS et al., 1996), trilobitas (ELDREDGE \& ORMISTON, 1979; SIMÕES et al., 2006), conulários (VAN ITEN, 1991; SIMÕES et al., 2000; RODRIGUES et al., 2003; VAN ITEN et al., 2013); e moluscos (KOTZAN, 1995; KOTZAN \& SIMÕES, 1997; WILLIAMS et al., 2000; WITTMER \& MILLER, 2011; SCHINDLER, 2012).

\section{GEOLOGIA DA ÁREA DE ESTUDO}

A Bacia Sedimentar do Paraná é classificada como uma bacia cratônica intercontinental de natureza policíclica. É uma sinéclise de grande extensão, que abrange os estados do Rio Grande do Sul, Santa Catarina, Paraná, São Paulo, Goiás, Mato Grosso do Sul e Mato Grosso, além dos países Paraguai oriental, Nordeste da Argentina e Norte do Uruguai, totalizando uma área de $1.500 .000 \mathrm{~km}^{2}$. Milani et al., (2007) reconheceram seis unidades aloestratigráficas ou Supersequências no registro estratigráfico da Bacia do Paraná, sendo as unidades Rio Ivaí (Ordoviciano-Siluriano), Paraná (Devoniano) e Gondwana I (Carbonífero-Eotriássico) representadas por pacotes sedimentares que definem ciclos transgressivo-regressivos relacionados à oscilações no nível do mar, enquanto que as unidades Gondwana II, Gondwana III e Bauru correspondem a pacotes de sedimentitos continentais com rochas ígneas associadas.

O Devoniano da Bacia do Paraná é dividido litoestratigraficamente pelas formações Furnas, Ponta Grossa e São Domingos (GRAHN, 1992; GAUGRIS \& GRAHN, 2006; MENDLOWICZ-MAULLER et al., 2009; GRAHN et al., 2010; e GRAHN et al., 2013).

\section{LOCALIDADES}

Seção Curva II (25 03' 58,97"' S, 5007' 39,00”' O; fig. 1)

Localiza-se na Zona 2 de Cruz (2008), no corte da estrada de ferro Central do Paraná, trecho Uvaranas-Apucarana, sub-trecho Uvaranas-Periquitos, Jardim Gianna, Ponta Grossa - Paraná. O acesso pode ser feito seguindo os trilhos a partir da Avenida Monteiro Lobato e Afloramento Curva I ou pelos fundos da Vila Jardim Gianna, situado na região nordeste da cidade de Ponta Grossa, Paraná.

O afloramento Curva II (fig. 2) é representado por um pacote de aproximadamente 7 metros de espessura, onde os primeiros 3 metros são compostos predominantemente por folhelho síltico argiloso cinza-amarelado, físsil, ricamente fossilífero com predominância do braquiópode Australospirifer spp. Intercaladas, ocorrem camadas de aproximadamente $0,5 \mathrm{~m}$ de arenito fino contendo estruturas sedimentares do tipo Hummocky Cross Stratification (HCS) e finas lentes de siltito. No terceiro metro, registra-se a ocorrência de uma fina camada (aproximadamente $0,3 \mathrm{~m}$ ) de arenito fino, apresentando níveis ferruginosos por vezes contendo fósseis. A partir do terceiro até o sétimo metro, a seção é cons- 
tituída por folhelhos sílticos cinza-amarelado e físsil, com intercalações de siltitos finos a médios, maciços, e estruturas sedimentares do tipo HCS ocorrem intercaladas nesses níveis. A paleofauna encontrada é composta por braquiópodes Rhynchonelliformes (Australocoelia palmata, Australospirifer spp., Derbyina sp., Schuchertella sp. e Cryptonella baini) e linguliformes (Orbiculoidea spp.); moluscos bivalves (Actinopteria langei) tentaculitídeos (Tentaculites spp.) e crinóideos.

Figura 1 - Mapa de localização das seções de estudo no município de Ponta Grossa-PR (adaptado de Cruz, 2008)

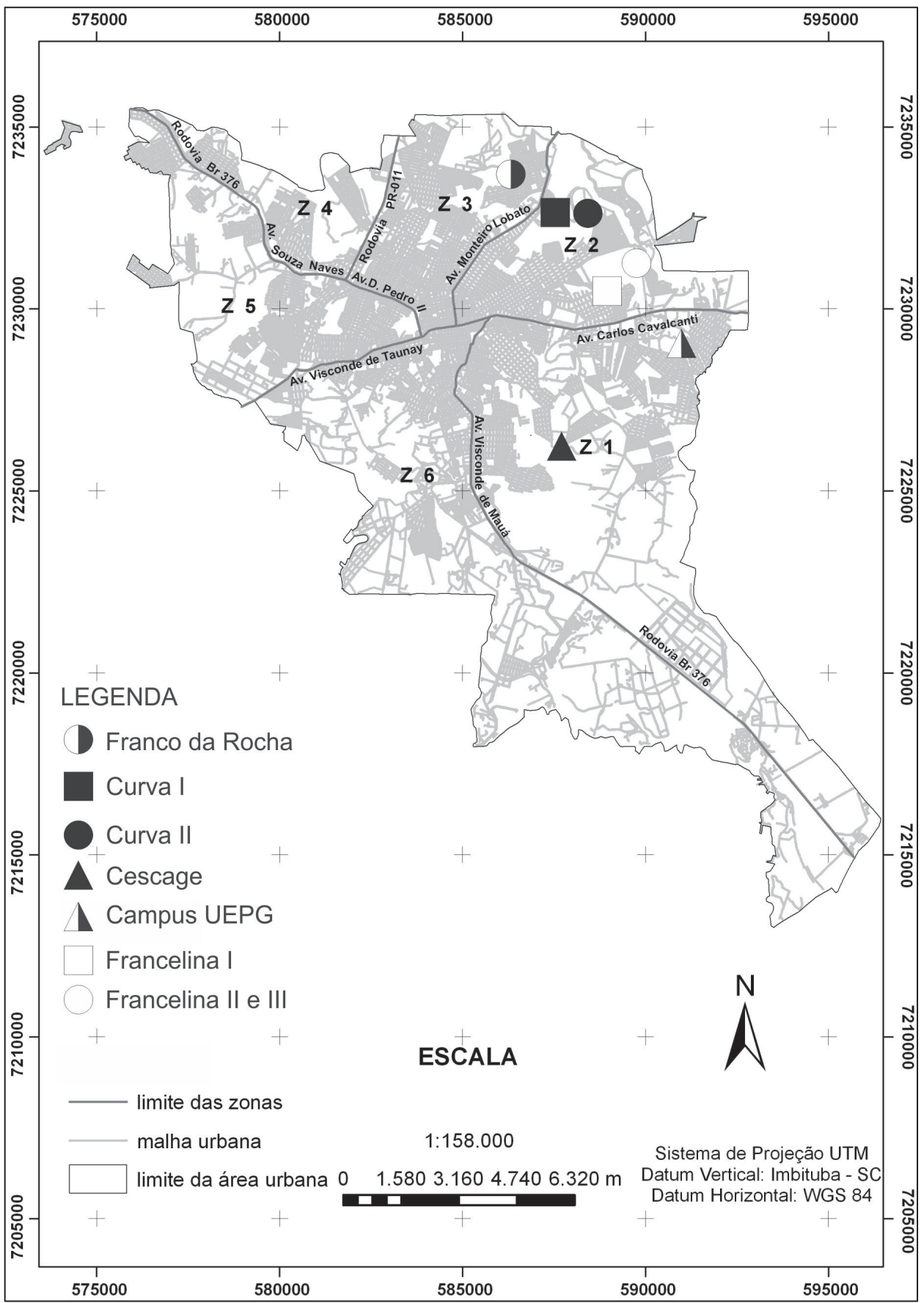


Seção Cescage $\left(25^{\circ} 05^{\prime} 86^{\prime \prime} \mathrm{S}, 50^{\circ} 07^{\prime} 95^{\prime \prime} \mathrm{O}\right)$

Está localizado na Zona 1 de Cruz (2008), próximo às instalações do Centro de Ensino Superior dos Campos Gerais - CESCAGE, campus Olarias. O acesso principal é feito através da intersecção da Avenida General Carlos Cavalcanti com a Rua Tomazina. A exposição de rocha possui 4,6 m de espessura, sua base é constituída litologicamente por um pacote de $1,5 \mathrm{~m}$ de siltito cinza-escuro fino, micáceo, sobreposto por uma camada de $0,9 \mathrm{~m}$ de siltito cinza-claro fino a médio (fig. 2). A porção média da seção é constituída por um nível de siltito cinza-claro fino intercalado por dois níveis de argilito amarelo-claro, todos com aproximadamente $0,6 \mathrm{~m}$ de espessura. Capeando a seção ocorre uma camada de arenito muito fino, maciço, bastante intemperizado no topo. Com exceção dos arenitos, toda a seção é abundantemente fossilífera. A paleofauna encontrada é composta por braquiópodes rhynchonelliformes (Australocoelia palmata, Australospirifer sp. Derbyina sp.) e linguliformes (Orbiculoidea sp.); moluscos tentaculitídeos (Tentaculites sp.) e ainda trilobites homalonotídeos e calmoniídeos.

Bosetti et al. (2009) descreveram tafonomicamente e correlacionaram estratigraficamente as seções denominadas Francelina ( $25^{\circ} 04^{\prime}$ 55,36" S, 50 06 52,86" O) e Campus UEPG ( $\left(25^{\circ} 05^{\prime} 33,00^{\prime \prime} \mathrm{S}, 50^{\circ} 06^{\prime} 15,19^{\prime \prime} \mathrm{O}\right)$. Os dados obtidos revelaram uma sucessão dos primeiros eventos paleoambientais ocorridos após o rápido recobrimento dos depósitos da Formação Furnas, caracterizando a base do trato de sistema transgressivo.

Grahn \& Bosetti, (2010) correlacionaram estratigraficamente as seções Curva I ( $25^{\circ}$ $03^{\prime} 55,88^{\prime \prime}$ S, $\left.50^{\circ} 08^{\prime} 00,06^{\prime \prime} \mathrm{O}\right)$ e Franco da Rocha ( $\left.25^{\circ} 03^{\prime} 21,43^{\prime \prime} \mathrm{S}, 50^{\circ} 08^{\prime} 10,18^{\prime \prime} \mathrm{O}\right)$ através dos dados altimétricos, litológicos e estratigráficos. Com exceção da seção Franco da Rocha (poço), as demais apresentam abundante fauna fóssil de invertebrados marinhos. A porção superior da seção Curva I e toda a seção Franco da Rocha (representada por folhelhos) representam a porção superior da Formação Ponta Grossa (ou o máximo transgressivo da Sequência B). 
Figura 2 - Correlação estratigráfica de superfície dos afloramentos estudados e distribuição estratigráfica das sucessões tafonômicas registradas

\section{SEQUÊNCIA NEOPRAGUIANA-EOEMSIANA}

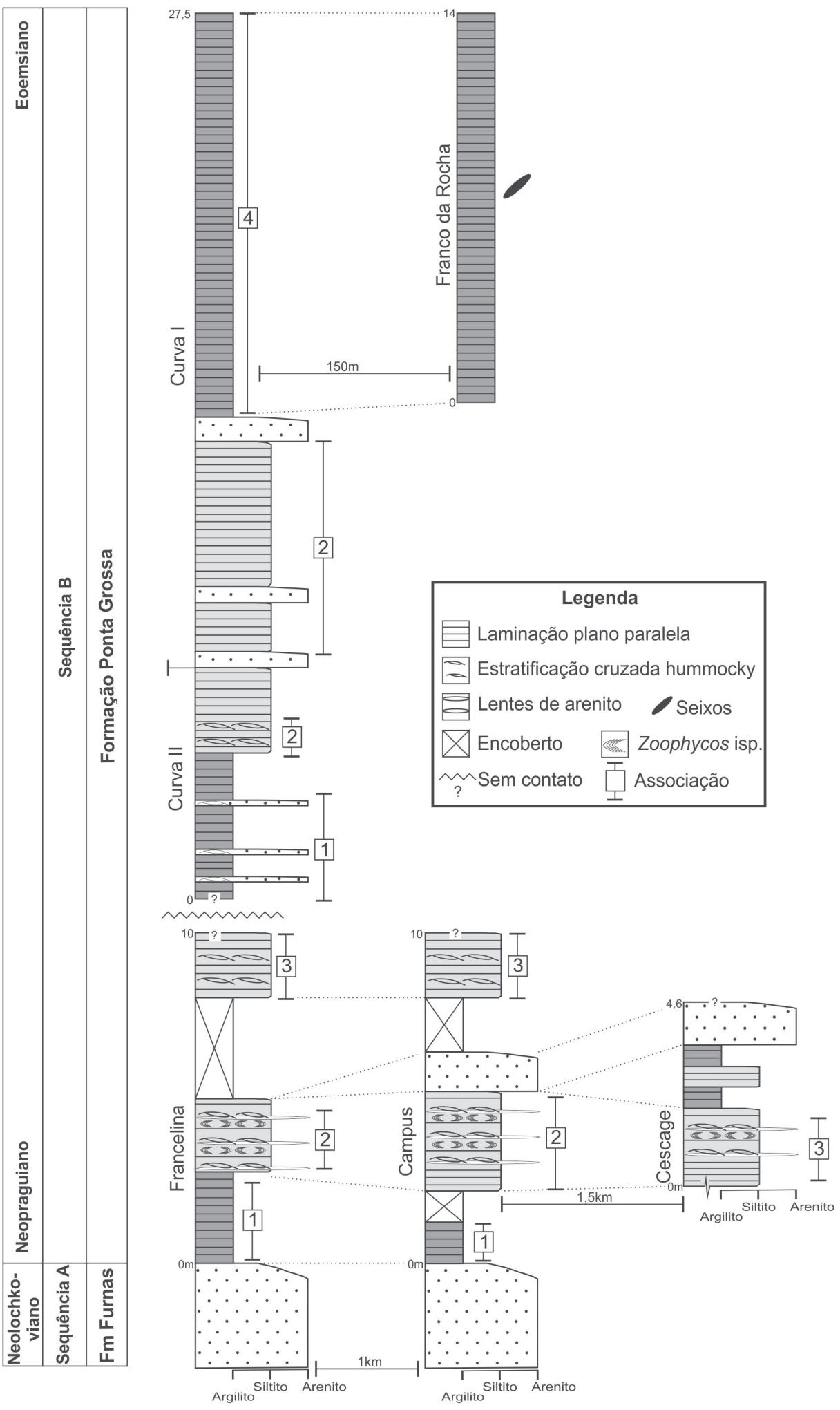




\section{RESULTADOS E DISCUSSÃO ASSOCIAÇÃO TAFONÔMICA 1}

A associação tafonômica 1 ocorre na base da seção Francelina, Campus e Curva II. Litologicamente é formada por folhelho argiloso preto, betuminoso, finamente laminado, com nódulos piritosos esféricos e centimétricos; ou por folhelho argiloso intercalado com camadas centimétricas de arenito muito fino a fino com HCS. Nessa associação, ocorrem animais com esqueleto do tipo bivalve (Lingulídeos infaunais, Orbiculoidea spp., Gigadiscina collis, Derbyina sp., Australocoelia palmata [fig. 3B e F], Australospirifer spp. [fig. 3A e G], Australostrophia sp., Actinopteria langei), univalve (Tentaculites sp.) e multielemento (crinóideos). Todas as valvas apresentaram-se inteiras, desarticuladas, concordantes ao plano de acamamento e fora da posição de vida. Não foram observados indícios de abrasão em nenhum dos bioclastos. Os tentaculitídeos (Tentaculites spp.) são representados nessa fácies por conchas inteiras, concordantes ao acamamento e sem orientação preferencial. Os braquiópodes organofosfáticos dos gêneros Gigadiscina collis e Orbiculoidea spp. estão no plano de acamamento e inteiros. Devido ao acentuado grau de achatamento dorso-ventral desses fósseis, somado à fina espessura das valvas, não foi possível verificar o grau de articulação desses bioclastos.

\section{INTERPRETAÇÃO}

A análise tafonômica dos bioclastos (valvas desarticuladas) dessa porção sugere que estes sofreram transporte significativo, podendo ser interpretados como alóctones (sensu SPEYER; BRETT, 1988; KIDWELL; BOSENCE, 1991). A presença de Gigadiscina collis, Orbiculoidea baini e O. bodenbenderi tem sido registrada, sem exceção, nos folhelhos pretos (offshore) da sucessão devoniana em todo o estado do Paraná, onde outros taxa (excetuando-se os lingulídeos infaunais, também de concha orgânica), são muito raros (ver ZABINI et al. 2010; 2012 e ZABINI \& COMNISKEY, neste volume). 
Figura 3 - Fósseis de macroinvertebrados ocorrentes na seção Curva II: A - Australospirifer iheringi, B Australocoelia palmata, C-D - Cryptonella baini, E - pluricolunal de Crinóide, G - Australocoelia palmata e F - Australospirifer iheringi
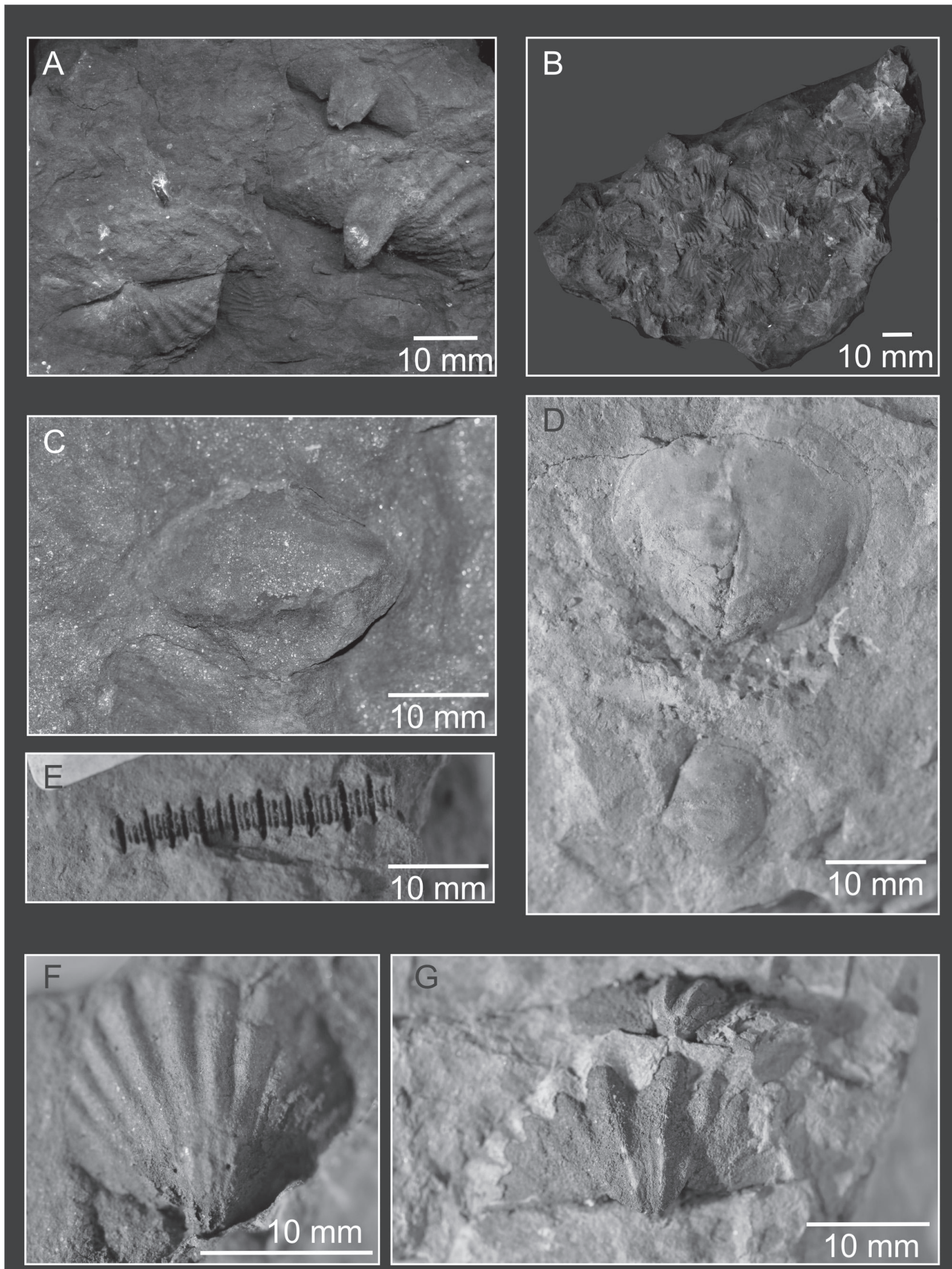
Devido ao hábito de vida dos discinídeos fósseis ser epibentônico séssil (SÜDKAMP, 1997; MERGL; MASSA, 2005; MERGL, 2010; COMNISKEY, 2011), a ocorrência marcante desse grupo em fácies de offshore com a valva braquial voltada para cima corrobora a hipótese de transporte do organismo e posterior recolonização do substrato. Zabini; Bosetti (2011) já diagnosticaram essa situação para os lingulídeos infaunais. Fernandés Lópes (1990) denominou de "condição subprimária" esse caso de "aloctonia", no qual os organismos foram transportados em vida e depositados em outras regiões. Ao introduzir esse termo, o autor discute que o processo de transporte (bioestratinomia) dos bioclastos pode ocorrer em vida. Esse novo termo contrasta com o que é atualmente empregado na tafonomia, i.e. transporte pós-morte (ver MARTIN 1999; BEHRENSMEYER et al., 2000; HOLZ; SIMÕES, 2002; SIMÕES et al. 2010).

O registro de Tentaculites spp., bem como dos demais bioclastos encontrados nessas camadas, é esporádico. O hábito de vida desse grupo é muito discutido. Segundo Wittmer \& Miller (2011) e Schindler (2012), esses animais seriam suspensívoros planctônicos na fase larval e bentônicos na fase adulta. Esses bioclastos não apresentaram orientação preferencial, indicando que a concentração pode ser fruto de remobilização por suaves fluxos de fundo ocasionados pelo movimento de correntes de fundo abaixo da NBOT, como citado por Rodrigues et al. (2001) em seções de Jaguariaíva (PR) e na época de sedimentação dos estratos referentes à base da seção Curva II pela presença de camadas centimétricas de arenito fino portadores de HCS.

\section{ASSOCIAÇÃO TAFONÔMICA 2}

A associação tafonômica 2 ocorre na porção mediana das seções Francelina e Campus UEPG, topo da seção Curva II e base da seção Curva I. Litologicamente, é representada por um pacote de folhelho síltico e siltito intensamente bioturbado por portadores de fósseis, intercalado com arenito muito fino a fino com estrutura HCS; ou por folhelho síltico intercalado com arenito fino a médio, preto e maciço. Nessa associação, ocorrem animais com esqueleto do tipo bivalve (Lingulídeos infaunais, Orbiculoidea spp., Australocoelia palmata, Australospirifer spp., Australostrophia sp., Derbyina whitiorum, Schuchertella sp. Cryptonella baini [fig. 3C e D]), multielemento (crinóideos [fig. 3E] e trilobite), de teca flexível (Conulatae), além de traços fósseis do icnogênero Zoophycos isp. Tafonomicamente, os bioclastos ocorrem em três modos preservacionais: (i) bivalves articulados em aparente posição de vida associados à Zoophycos isp.; (ii) bivalves desarticulados posicionados concordantemente ao plano de acamamento associados a HCS; e (iii) bivalves articulados em aparente posição de vida associados a HCS. A atividade biogênica intraestratal, representada pelo Zoophycos isp., é intensa naqueles pacotes (grau de bioturbação entre 4 e 5 na escala de REINECK, 1963). Essa atividade é composta por bioturbações ora paralelas ao plano de acamamento ora inclinadas em relação a este. Destacam-se traços fósseis pertencentes ao icnogênero Zoophycos isp.; essa bioturbação resulta em uma estrutura mosqueada (mottled structure) que dificulta a interpretação sedimentológica, 
uma vez que destrói as estruturas sedimentares pré-existentes. Representa, porém, um marco estratigráfico na área estudada. Por vezes, essas zonas de bioturbação alteram a posição original dos bioclastos previamente soterrados (ZABINI, 2007). Essas feições apresentam-se estratigraficamente intercaladas a estruturas HCS de pequeno porte, onde os bioclastos encontram-se desarticulados e no plano de acamamento.

\section{INTERPRETAÇÃO}

A sucessão de fácies presentes na associação tafonômica 2 (folhelhos sílticos, siltitos e arenitos), aponta situação de deposição em águas mais rasas em relação a associação tafonômica 1, ocasionalmente perturbadas por ondas de tempestades no offshore transicional. Essa hipótese pode ser corroborada pela análise tafonômica dos bioclastos (valvas desarticuladas e concordantes ao plano de acamamento) e pela presença de estruturas HCS. Intercaladas aos eventos de maior energia, ocorrem camadas intensamente bioturbadas, associadas à bioclastos em aparente posição de vida (lingulídeos infaunais). Nessas camadas, é possível distinguir dois eventos sucessivos: (i) os lingulídeos infaunais foram transportados para ambientes mais distais onde puderam re-escavar e recolonizar o substrato (ZABINI; BOSETTI, 2011; ZABINI et al. 2010; 2012), permanecendo em aparente posição de vida (condição subprimária sensu FERNANDÉS LÓPES, 1990); (ii) posteriormente, após a subida do nível de base, esses níveis foram bioturbados pelo organismo produtor de Zoophycos que reorientou o posicionamento original dos lingulídeos infaunais (GODOY et al. 2005; ZABINI, 2011; ZABINI et al. 2010; 2012). As rochas portadoras desses traços fósseis geralmente indicam paleoambientes de sedimentação mais profundos, junto ao NBOT (pacotes com Zoophycos) e abaixo do NBON (arenitos com HCS). Essa situação cíclica (HCS e bioturbação intercaladas) ocorre em todo o intervalo descrito. Nas seções estudadas, Zoophycos encontra-se também associado, diacronicamente, aos braquiópodes lingulídeos infaunais, discinídeos e Australocoelia palmata, todos em aparente posição de vida. Tal feição tafonômica sugere soterramento por sedimentos transportados em correntes durantes eventos de tempestades, conforme também observado por Zabini et al. (2010). A posterior decomposição das partes moles desses invertebrados enriqueceu os sedimentos em matéria orgânica, favorecendo a imediata colonização por produtores de Zoophycos, produzidos por organismos detritívoros que suportam níveis inferiores de oxigenação, pois geralmente vivem dentro do substrato e colonizam tiers mais profundos (UCHMAN, 1995; BROMLEY; EKDALE, 1984; BROMLEY, 1996; BUATOIS; MANGANO, 2011).

No topo da seção Curva II, ocorrem agrupamentos distintos de Australospirifer spp. e Australocoelia palmata em aparente posição de vida, preservados em folhelho síltico com HCS. Associados, são encontrados valvas desarticuladas de braquiópodes, pluricolunais de crinóides, pigídio completo de trilobita homalonotídeo e conulários rasgados e achatados, todos paralelos ao plano de acamamento. Segundo Simões et al. (1999), agrupamentos de invertebrados bentônicos epifaunais em posição de vida são raros nos 
sedimentitos Paleozoicos da Bacia do Paraná. O mesmo autor identificou agrupamentos de Australospirifer iheringi em modo de vida corpo sustentado (corp-supportive) no Devoniano da Bacia do Paraná. Comniskey (2011) também registrou em ambientes de shoreface proximal a distal agrupamentos de discinídeos do gênero Orbiculoidea, todos com espécimes apresentando-se com valvas inteiras, articuladas e em posição de vida (valva pedicular com convexidade para baixo). A partir desses registros, pode-se inferir que os bioclastos em aparente posição de vida associados aos bioclastos desarticulados foram transportados do shoreface para o offshore transicional. Portanto, essa associação é considerada como alóctone, preservada entre o nível de base de ondas normais (NBON) e o nível de base de ondas de tempestade (NBOT). Semelhante aos lingulídeos infaunais e discinídeos, os braquiópodes Rhynchonelliformes aqui registrados em aparente posição de vida podem ter sidos transportados ainda em vida e tentado se fixar no substrato até o soterramento final, caracterizando o modo de preservação em condição subprimária. A mistura temporal (KIDWELL; BOSENCE, 1991) pode ser identificada por meio da ocorrência associada nesse pacote de conulários rasgados, valvas e peças desarticuladas mais antigas.

Nesse contexto, são identificadas, nesses pacotes, três situações de aloctonia distintas: i) camadas bioturbadas por Zoophycos e presença de lingulídeos infaunais em aparente posição de vida caracterizam depósitos de soterramento e situação de aloctonia com os lingulídeos preservados em condição subprimária abaixo do NBON; (ii) camadas que possuem HCS associados aos agrupamentos de Australocoelia palmata e Australospirifer spp. também preservados em condição subprimária; e (iii) camadas que possuem HCS e bioclastos inteiros, desarticulados e paralelos ao plano de acamamento preservados entre o NBON e o NBOT.

\section{ASSOCIAÇÃO TAFONÔMICA 3}

A associação tafonômica 3 ocorre no topo das seções Francelina e Campus UEPG e base da seção Cescage. Litologicamente, é representada por um pacote de siltito muito bioturbado (com presença de Zoophycos [fig. 4D]), sendo este caracterizado por siltito grosso, maciço, com nódulos e concreções ferruginosas, contendo fósseis bem preservados. Lentes centimétricas de arenito muito fino a fino são presentes e ocasionalmente encerram material fóssil. Nessa associação, ocorrem animais com esqueleto do tipo bivalve (Lingulídeos infaunais, Orbiculoidea sp., Australocoelia palmata [fig. 4B], Australospirifer spp., Australostrophia sp., Derbyina whitiorum, Schuchertella sp., Pleurodapis sp. e Nuculites sp.), multielemento (crinóideos e trilobite calmoniídeo [fig. 4C] e homalonotídeo [fig. 4A]), univalve (Tentaculites spp., Belerophontidae), e de teca flexível (Conulatae). A característica que distingue essa fácies é a surpreendente quantidade de bioclastos, notadamente de trilobites. Em sua maioria, os bioclastos apresentam-se desarticulados, como valvas de braquiópodes e peças de trilobitas (céfalo, tórax, pigídio, céfalo-tórax, tórax pigídio e somitos toráxicos) no plano de acamamento. No entanto, lingulídeos e co- 
nulários em aparente posição de vida, além de exúvias de trilobitas de ocorrência in situ (como carcaças estendidas, enroladas e modo salteriano de preservação) também foram registradas em níveis distintos. Na seção Cescage, em particular, além da ocorrência de exúvias de trilobitas homalonotídeos em modo salteriano de preservação, encontrou-se ainda Zoophycos e valvas articuladas fechadas de Australocoelia palmata (fig. 4).

\section{INTERPRETAÇÃO}

A característica distintiva desses pacotes é a surpreendente quantidade de bioclastos presentes, notadamente dos trilobitas (Homalonotidae e Calmoniidae), que são o grupo predominante na associação (isso não ocorre em outras áreas, onde o grupo sempre é o mais raro) (BOSETTI et al., 2009). Segundo Eldredge \& Orminston (1979), os trilobites homalonotídeos são indicadores de águas mais rasas. Observações da distribuição faciológica dos homalonotídeos, baseadas em integração detalhada de estratigrafia de sequências e dados tafonômicos foram, pela primeira vez, referidas na literatura por Simões et al. (2006) para a seção Francelina. Segundo os autores, esses trilobites são invertebrados dependentes de fácies, preferencialmente ocorrendo em depósitos siliciclásticos de plataforma rasa.

Os trilobitas coletados nas seções Francelina e Campus UEPG enquadram-se em condições deposicionais mais energéticas, portanto, essas concentrações são representantes da Tafofácies TII de Soares (2007) e Simões et al. (2009), as quais foram preservadas em arenitos finos a siltitos, tendo sido geradas sob condições de águas rasas acima ou no nível de base de ondas normais (NBON) ocorrentes na porção basal da Formação Ponta Grossa. 
Figura 4 - Fósseis registrados na seção Cescage: A - Trilobite Homalonotidae em modo salteriano; B Australocoelia palmata; C - Pigídeo de trilobite Calmoniídeo e D - icnogênero Zoophycos isp.
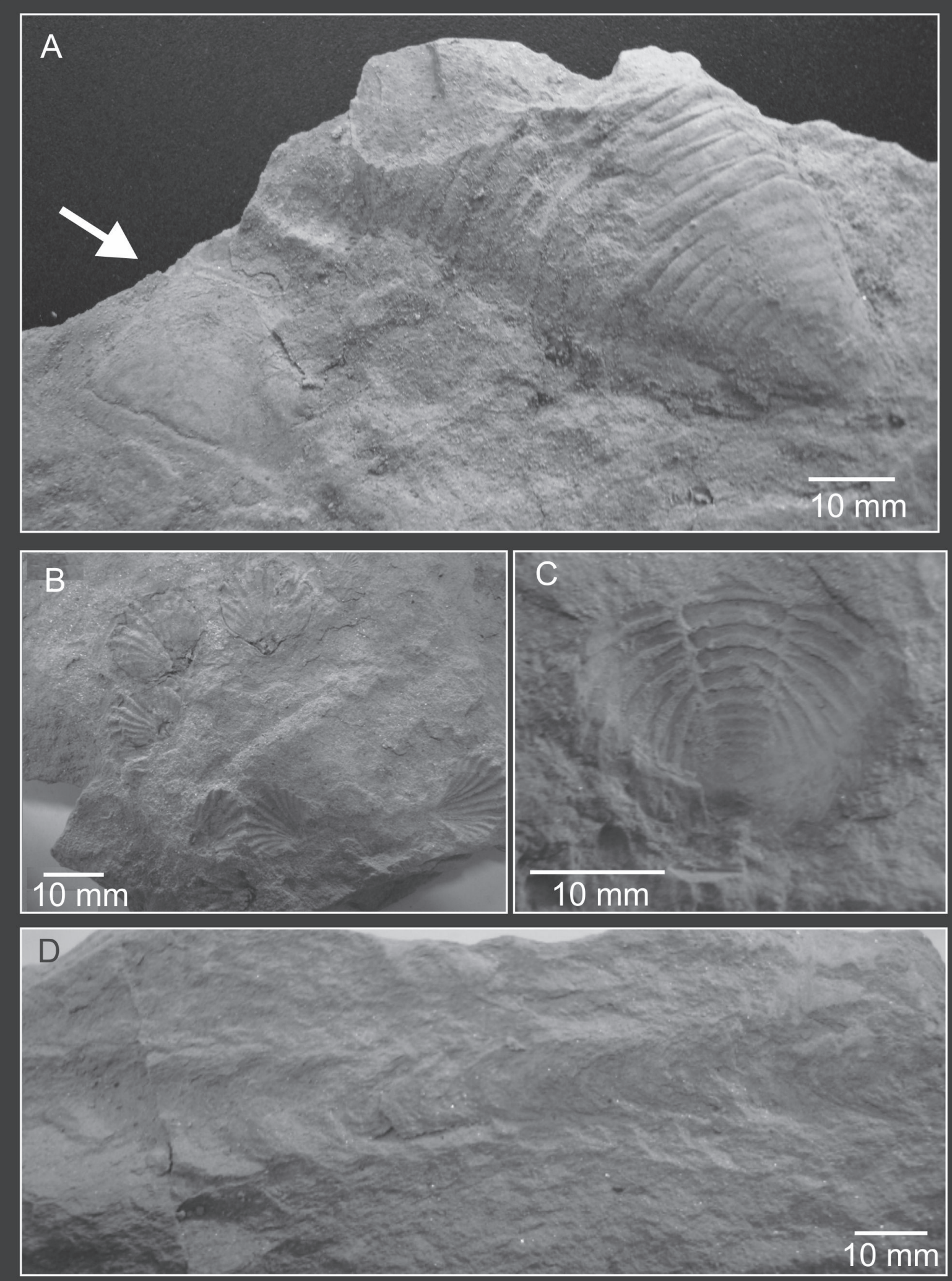
Simões et al. (2006) assinalaram que, embora dados batimétricos absolutos não possam ser determinados com base na presença de homalonotídeos, dados sedimentológicos, estratigráficos e tafonômicos indicam que esses trilobitas viveram e/ou ficaram preservados em depósitos de águas rasas acima do NBON. Nesses pacotes, os trilobitas encontram-se associados aos braquiópodes do gênero Australospirifer e Australocoelia, em aparente posição de vida. Segundo Boucot (1983), os esperiferídeos, de modo geral, apresentam anatomia indicativa de suporte adaptativo a ambientes com maior energia. Cnidários (Conulatae) associados a trilobitas homalonotídeos foram, pela primeira vez, registrados na sequência B por Bosetti (2004). Esses conulários são representados por dois espécimes inclinados, com a base convergindo para um centro comum e podem ser classificados na classe tafonômica 2 de Rodrigues (2002). Essa classe reúne conulários cujo eixo maior da teca mostra-se inclinado em relação ao plano de acamamento, incluindo espécimes isolados ou agrupados. Em contraste com as interpretações de Rodrigues (2002) e Rodrigues et al. (2003), que citam os conulários inclinados como sendo indicadores de condições de deposição abaixo do NBOT, a somatória dos dados litológicos (textura grossa ocorrente nessas camadas) às demais evidências acima mencionadas corrobora a interpretação de um ambiente de águas mais rasas para essa fácies estudadas. Portanto, o conjuntos das características sedimentológicas e tafonômicas do material estudado das seções Francelina e Campus UEPG permite reconhecer a Associação tafonômica 3 como situação de autoctonia onde os bioclastos foram preservados no NBON ou acima deste.

No caso em especial do afloramento Cescage, as assinaturas tafonômicas dos invertebrados (homalonotídeos preservados em modo salteriano e braquiópodes articulados fechados), em conjunto com os dados sedimentológicos (siltito) sugerem que os bioclastos são autóctones. Nesse pacote sedimentar, é possível reconhecer dois eventos distintos: (i) os trilobitas e braquiópodes foram soterrados in situ junto ou abaixo do NBON. Posteriormente, houve variação no nível de base com aumento do nível do mar, sendo então registrado o segundo evento; (ii) colonização de Zoophycos isp. no NBOT. Portanto, esse icnofóssil foi preservado diacronicamente com os invertebrados (fig. 5). Essa porção basal do afloramento Cescage é tafonomicamente semelhante às porções de topo dos afloramentos Francelina e Campus UEPG. O registro diácrono de Zoophycos isp. sugere apenas laterialidade entre os pacotes sedimentares. 
Figura 5 - Representação dos eventos tafonômicos e sedimentares registrados para a Associação Tafonômica 3 no afloramento Cescage. A distribuição batimétrica dos trilobitas homalonotídeos segue Sandford,

(2005) e Simões et al. (2009). A nomenclatura estratigráfica segue Walker; James, (1992) e Walker; Plint

(1992). A - Trilobitas homalonotídeos habitando regiões proximais de shoreface acima e abaixo do NBON e Zoophycos isp. colonizando regiões distais no offshore abaixo do NBOT. B - Soterramento in situ dos trilobitas homalonotídeos por tempestito proximal. C - Subida do nível do mar com os depósitos de trilobitas sendo retrabalhado pelo Zoophycos isp. no offshore abaixo do NBOT. NRM., Nível relativo do mar, NBON.,

Nível de base de ondas normais, NBOT., Nível de base de ondas de tempestade.

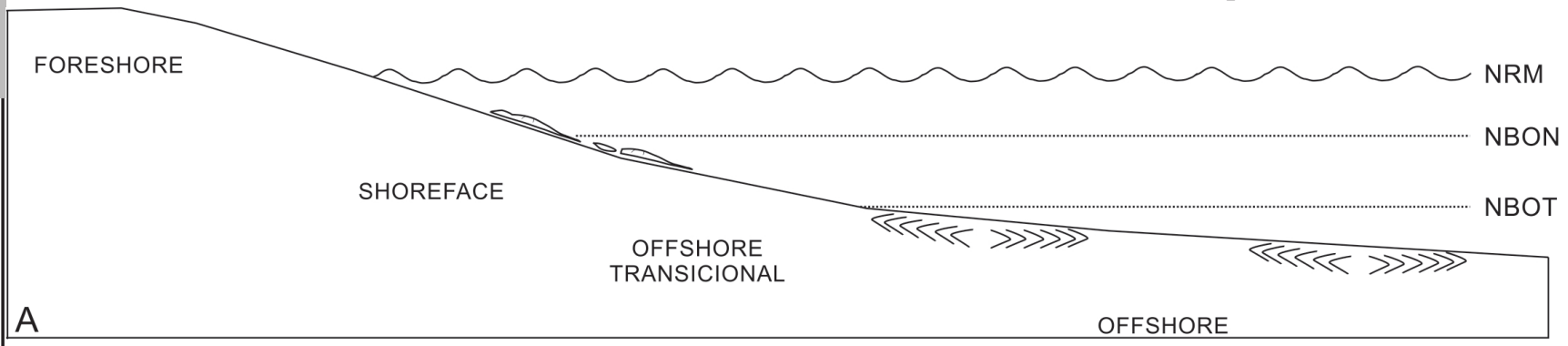

A

OFFSHORE

$\rightarrow$ Zoophycos isp. $\propto$ Trilobites Homalonotídeos $\propto$ Mudas de trilobites Homalonotídeos

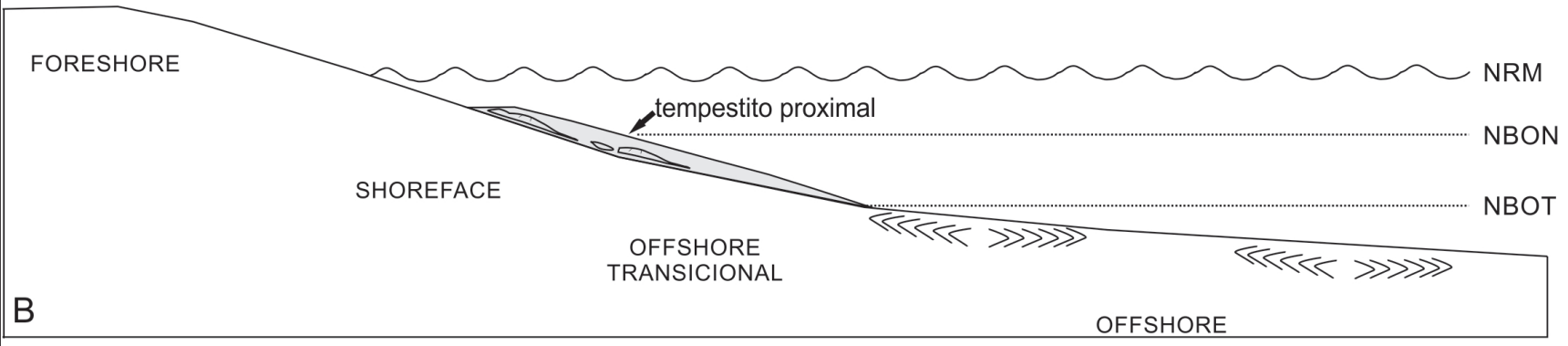

B

$\rightarrow$ Zoophycos isp. $\sim$ Restos de trilobites Homalonotídeos soterrados

C

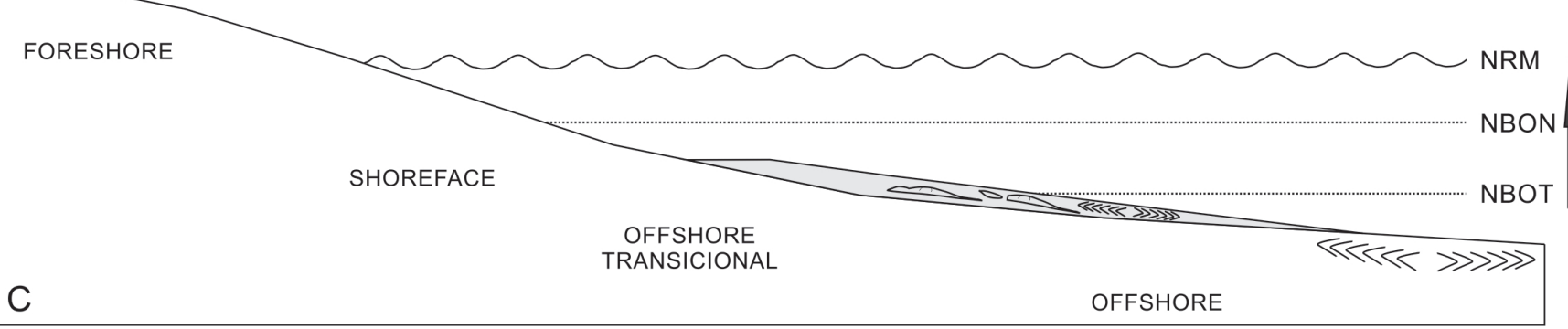

$\gg$ Zoophycos isp.

Carcaças completas de

Homalonotídeos

Homalonotídeos em modo salteriano

Subida do nível do mar

\section{ASSOCIAÇÃO TAFONÔMICA 4}

A associação tafonômica 4 ocorre somente no topo da seção Curva I. Litologicamente, é representada por um pacote de folhelho argiloso preto, carbonoso e físsil. Nessa associação, ocorrem animais com esqueleto do tipo bivalve (Lingulídeos infaunais, Orbiculoidea spp., Australocoelia palmata, Australospirifer sp., Australostrophia sp., Derbyina whitiorum, Schuchertella sp., Pleurodapis sp. e Nuculites sp.) e multielemento (crinóideos e trilobite), univalve (Tentaculites sp., Belerophontidae). Tafonomicamente, todos os bio- 
clastos apresentam-se inteiros e articulados (com exceção dos univalves). Em seções correlatas (seções Franco da Rocha e Tibagi 2), Grahn \& Bosetti (2010) registraram seixos em folhelhos pretos associados a braquiópodes Australospirifer sp. e lentes de arenito fino portadores de HCS.

\section{INTERPRETAÇÃO}

A sucessão de fácies presentes na associação tafonômica 4 (folhelho preto) aponta situação de deposição em águas mais profundas que ocasionalmente foram perturbadas por ondas de tempestades no offshore. A tafonomia e a paleoecologia da fauna sugere que os bioclastos foram transportados de seu habitat, de regiões proximais, para ambientes distais no offshore abaixo do NBOT, através da ação de correntes de retorno causadas por tempestades (BRETT \& SEILACHER, 1991). Esses organismos puderam recolonizar o substrato, permanecendo articulados e em aparente posição de vida (condição subprimária).

\section{CORRELAÇÃO}

A Sequência B (BERGAMASCHI, 1999; BERGAMASCHI \& PEREIRA, 2001; GRAHN et al., 2013), conforme já discutida anteriormente, é caracterizada por apenas apresentar em seções de superfície o trato de sistema transgressivo (TST). Segundo Antunes; Melo (2001), Catuneanu et al. (2009; 2010), a sedimentação de um TST é retrogradacional a agradacional, limitada em sua base pelo trato de sistemas de nível baixo (TSNB), e em sua porção superior pela máxima transgressiva (SMT) e posteriormente pelo trato de sistemas de nível alto (TSNA). Os afloramentos Francelina I, II e III, Campus UEPG, Curva I e Franco da Rocha, já foram anteriormente posicionados estratigraficamente nessa sequência (c.f. RODRIGUES, 2002; BOSETTI, 2004; HORODYSKI et al., 2006; BOSETTI et al., 2009; GRAHN et al., 2010; GRAHN \& BOSETTI, 2010; ZABINI et al. 2010; MYSZYNSKI JUNIOR, 2012).

O afloramento inédito aqui descrito e denominado Cescage (base) está posicionado estratigraficamente na base da Sequência B. Apesar de os atributos tafonômicos parecerem indicar os mesmos aspectos diagnosticados nas porções de topo dos estratos dos afloramentos Francelina e Campus UEPG (associação 3; veja fig. 2), a paleofauna encontrada e seus respectivos atributos tafonômicos (e.g. associação diácrona de homalonotideos em modo salteriano e ocorrência de Zoophycos) sugerem que essa associação seja representante de um ambiente mais raso em comparação com os estratos médios dos afloramentos acima citados, porém, abaixo do nível de base de ondas normais (com posteriores subidas do nível de base e colonização de fundo de Zoophycos) (ver fig. 5). Isso se justifica devido à presença marcante de Zoophycos aqui considerada como um marco estratigráfico, inclusive sendo também observado em camadas ricamente bioturbadas na seção de Jaguariaíva (veja RODRIGUES et al., 2003; ou para uma revisão 
com maior ênfase na icnologia desses depósitos, veja NETTO et al., 2012). Esse parece ser um horizonte único registrado em parte da porção basal da sequência B (Formação Ponta Grossa) no contexto transgressivo dessa sequência.

O afloramento Curva II (inédito) tem posicionamento geográfico muito próximo ao Curva I (620 m), e estratigraficamente está $2 \mathrm{~m}$ abaixo (base do Curva I $881 \mathrm{~m}$ - topo do Curva II $879 \mathrm{~m}$ de altitude). Litologicamente, os dois afloramentos mostram muitas semelhanças, bem como as típicas características de um TST. Ademais, o paradigma da distribuição vertical de macroinvertebrados em uma sucessão marinha, mostra-se, via de regra, com uma tendência na diminuição na abundância de indivíduos e de paleobiodiversidade, devido ao deslocamento da linha de costa em direção ao continente e, consequentemente, da zona hipotética de habitação dos organismos ali viventes (SPEYER \& BRETT, 1986; 1988; HOLLAND, 1995; BRETT, 1997; HOLZ et al. 2010). Essa é uma característica observada entre o afloramento Curva I (mais abundante em número de indivíduos e de paleobiodiversidade) e Curva II. O topo da seção local (Curva I e Franco da Rocha) no município de Ponta Grossa culmina com o máximo transgressivo da sequência B da Formação Ponta Grossa, que pode ser também observado nas camadas referentes a essa sequência nas seções Jaguariaíva (RODRIGUES 2002; GHILARDI, 2004 e GRAHN et al. 2013) e Tibagi-Telêmaco Borba (BERGAMASCHI, 1999 e BERGAMASCHI \& PEREIRA, 2001; veja uma atualização mais recente em GRAHN et al., 2013). Portanto, somado aos dados de Bosetti et al., (2009), conclui-se aqui que as seções que representam os primeiros momentos do TST da Sequência B na região de Ponta Grossa são: Francelina, Campus UEPG e Cescage. Em Bosetti (2004), Grahn \& Bosetti (2010) e Myszynski Junior (2012), a base do afloramento Curva I foi posicionada na porção média do TST e o topo do Curva I e Franco da Rocha na base do máximo transgressivo.

Por meio de todas as características em conjunto (altitude, proximidade geográfica, litologia, abundância de indivíduos e paleobiodiversidade), posiciona-se o afloramento Curva II acima das seções Francelina, Campus UEPG e abaixo do afloramento Curva I (fig. 2).

\section{CONCLUSÕES}

O estudo tafonômico desenvolvido aqui nas novas seções estratigráficas de superfície denominadas Cescage e Curva II forneceram dados que, em conjunto com as demais seções correlacionadas, foram suficientes para se diagnosticar ambientes de shoreface a offshore em toda a Sequência B da Formação Ponta Grossa.

Nas regiões mais proximais (próximo ao $\mathrm{NBON}$ ), o fator determinante para o tipo de concentração fossilífera foi o de tempestito proximal, resultando em bioclastos inteiros, o que justifica as assinaturas tafonômicas reconhecidas (conulários e braquiópodes em aparente posição de vida, trilobitas preservados em modo salteriano e enrolados em posição de estresse). 
As mudanças dos níveis de base registraram a ocorrência diácrona entre bioclastos autóctones a parautóctones previamente soterrados in situ, com organismos geradores de Zoophycos isp. Esses níveis altamente bioturbados por Zoophycos são aqui considerados como um horizonte estratigráfico único, podendo ser reconhecidos em pelo menos três seções estratigráficas de superfície de mesma idade, sendo elas: seções de Jaguariaíva (RODRIGUES 2002; NETTO et al., 2012), Tibagi (ZABINI et al., 2010; 2012) e agora, em Ponta Grossa.

Em ambientes de offshore transicional a offshore (acima e abaixo do NBOT), os bioclastos foram transportados por correntes de retorno causadas por tempestades (tempestido distal), das regiões mais proximais (shoreface), para as mais distais.

Destaca-se que, possivelmente, o registro tafonômico de associações fósseis influenciadas por eventos de tempestade são aqui consideradas como condição subprimária (ocorrência alóctone causada por transporte em vida, sensu FERNANDES LOPES, 1990). Essas novas interpretações auxiliam nos estudos paleoambientais, paleoautoecológicos, além da possibilidade de estimar a magnitude dos eventos de tempestade que atuaram na formação das concentrações fossilíferas aqui estudadas.

\section{AGRADECIMENTOS}

Os autores agradecem ao Conselho Nacional de Desenvolvimento Científico e Tecnológico (CNPq) e à Coordenação de Aperfeiçoamento de Pessoal de Nível Superior (CAPES), pelo apoio através da concessão de bolsas (CNPq Processos 150239/2011-4; 141979/2011-9 e 141256/2010-9) e auxílios (Processo 401796/2010-8), fundamentais para a realização deste trabalho e a Dra. Mercedes Di Pasquo (CICYTTP/CONICET) pela tradução do resumo.

\section{REFERÊNCIAS}

ANTUNES, Rogério, Loureiro; MELO José, Henrique Gonçalves. Micropaleontologia e estratigrafia de seqüências. In: RIBEIRO, Hélio Jorge Portugal Severiano (ed). Estratigrafia de Sequências - fundamentos e aplicações. São Leopoldo: Editora Unisinos, 2001, p. 137-218.

BEHRENSMEYER, Anna; KIDWELL, Susan; GASTALDO, Robert. Taphonomy and Paleobiology. Paleobiology, vol. 26, n. 4, 2000, p. 103-144.

BERGAMASCHI, Sérgio. Análise estratigráfica do Siluro-Devoniano (Formações Furnas e Ponta Grossa) da sub-bacia de Apucarana, Bacia do Paraná, Brasil. 1999. Tese (Doutorado em Geociências). Instituto de Geociências, Curso de Pós-Graduação em Geociências, Universidade de São Paulo, São Paulo.

BERGAMASCHI, Sérgio; PEREIRA, Egberto. Caracterização de sequências deposicionais de $3^{\text {a }}$ ordem para o Siluro-Devoniano na sub-bacia de Apucarana, Bacia do Paraná, Brasil. Ciência-Técnica-Petróleo, seção: Exploração de Petróleo. Rio de Janeiro, vol. 20, 2001.

BOSETTI, Elvio Pinto. Paleontologia do Lingulida (Brachiopoda: Inarticulata) da Formação Ponta Grossa, Devoniano, Bacia do Paraná, Brasil. 1989, Dissertação. (Programa de Pós-graduação em Geociências), Universidade Federal do Rio Grande do Sul, Porto Alegre. 
BOSETTI. Elvio Pinto. Tafonomia de alta resolução das fácies de offshore da sucessão devoniana da região de Ponta Grossa - Paraná, Brasil. 2004, Tese (Doutorado em Geociências - Instituto de Geociências, Curso de Pós-Graduação em Geociências), Universidade Federal do Rio Grande do Sul, Porto Alegre.

BOSETTI, Elvio Pinto; GODOY, Luiz Carlos; MYSZINSKI JUNIOR, Lucinei José, HORODYSKI, Rodrigo Scalise; ZABINI, Carolina. Interpretação paleoambiental na sequência basal da formação Ponta Grossa (devoniano) do município de Ponta Grossa, Paraná, Brasil. Terr@Plural, v. 3, n. 1, p.137-156. jan./jul. 2009.

BOUCOT, Arthur. Principles of Benthic Marine Paleoecology. New York: Academic Press, 1983.

BRETT, Carlton E.;SEILACHER, Adolf. Fossil Lagerstätten a taphonomic consequence of event sedimentation. EINSELE, Gerhard; RICKEN, Werner; SEILACHER, Adolf (eds). Cycles and Events in stratigraphy. Berlin: Springer-Verlag, 1991, p. 283-297.

BRETT, Carlton; MOFFAT, Heather; TAYLOR, Wendy. Echinoderm taphonomy, taphofacies, and lagerstätten. Paleontological Society Papers, v. 3, 1997, p. 147-190.

BROMLEY, Richard Granville. Trace fossils: Biology, taphonomy and aplications. Londres: Chapman \& Hall, 1996.

BROMLEY Richard Granville; EKDALE, Allan. Chondrites: a trace fossil indicator of anoxia in sediments. Science, v. 224, 1984, p. 872-874.

BUATOIS, Luis Alberto; MÁNGANO, María Gabriela. Ichnology: Organism-Substrate Interactions in Space and Time. New York: Cambridge University Press, 2011.

CATUNEANU, Octavian; ABREU, Vitor; BHATTACHARYA, Janok; BLUM, Michael;DALRYMPLE, Robert; ERIKSSON, Patrick; FIELDING, Cristopher; FISHER, William; GALLOWAY, William; GIBLING, Martin; GILES, Katherine; HOLBROOK, John; JORDAN, Robert; KENDALL, Christopher; MACURDA, Brad; MARTINSEN, Ole; MIALL, Andrew; NEAL, Jack; NUMMEDAL, Dag; POMAR, Louis; POSAMENTIER, Henry; PRATT, Brian; SARG, Rick; SHANLEY, Keith; STEEL, Ronald; STRASSER, Andreas; TUCKER, Maurice; WINKER, Charles. Towards the standardization of sequence stratigraphy. Earth-Science Review, 92, p. 1-33, 2009.

CATUNEANU, Octavian.; BHATTACHARYA, Janok; BLUM, Michael; DALRYMPLE, Robert; ERIKSSON, Patrick; FIELDING, Cristopher; FISHER, William; GALLOWAY, William; GIANOLLA, Piero; GIBLING, Martin; GILES, Katherine; HOLBROOK, John; JORDAN, Robert; KENDALL, Christopher; MACURDA, Brad; MARTINSEN, Ole; MIALL, Andrew; NEAL, Jack; NUMMEDAL, Dag; POSAMENTIER, Henry; PRATT, Brian; SHANLEY, Keith; STEEL, Ronald; STRASSER, Andreas; TUCKER, Maurice. Sequence stratigraphy: common ground after three decades of development. First Break 28, p. 21-34, 2010.

CLARKE, John Mason. Fósseis devonianos do Paraná. Monografia do serviço geológico e mineralógico do Brasil, 1913.

COMNISKEY, Jeanninny Carla. Paleontologia dos Discinidae (Brachiopoda: Linguliformea) da sucessão devoniana da Bacia do Paraná, Estado do Paraná, Brasil: Revisão Sistemática, Distribuição Geográfica e Estratigráfica. 2011. Dissertação (Mestrado em Gestão do Território). Programa de Pós-Graduação em Geografia, UEPG, Ponta Grossa.

CRUZ, Suzana de Fátima Camargo Ferreira da. Paleontologia e Geografia - uma abordagem TeóricoMetodológica a partir dos sítios paleontológicos existentes na área urbana de Ponta Grossa - PR. 2008. Dissertação (Mestrado em Gestão do Território). Programa de Pós-Graduação em Geografia, UEPG, Ponta Grossa.

ELDREDGE, Niles; ORMISTON, Allen. Biogeography of silurian and Devonian trilobites of the Malvinokaffric Realm. In: GRAY, Jane; BOUCOT, Arthur J. (eds) Historical biogeography, plate tectonics and the changing environment. Corvallis, Oregon State University, 1979, p.147-167.

FERNANDES LOPES, Sixto. El significado de la autoctonia/Aloctonia Tafonomica. COM. REUNIÓN DE TAFONOMÍA Y FOSILIZACIÓN, Madrid. 1990, p. 115-124.

GAUGRIS, Kariny de Amorim; GRAHN, Yngve. New chitinozoan species from the Devonian of the Paraná Basin, south Brazil, and their biostratigraphic significance. Ameghiniana, v. 43, n. 2, 2006, p. 293-310. 
GHILARDI, Renato Pirani. Tafonomia comparada e paleoecologia dos macroinvertebrados (ênfase em trilobites), da Formação Ponta Grossa (Devoniano, Sub-bacia Apucarana), estado do Paraná, Brasil. 2004, Tese (Doutorado em Geologia Sedimentar). Programa de Pós-Graduação em Geologia Sedimentar, USP, São Paulo-SP.

GODOY, Luiz Carlos; BOSETTI, Elvio Pinto ; HORODYSKI, R. S. Icnitos do gênero Zoophycos na sequência devoniana da bacia do Paraná, Ponta Grossa, Paraná, Brasil. In: VII PALEO PR/SC 2005, Ponta Grossa/ PR. Anais de resumos.

GRAHN, Yngve. Revision of Silurian and Devonian Strata of Brazil. Palynology, Dallas, n. 16, 1992.

GRAHN, Yngve; BOSETTI, Elvio Pinto. Storm deposited pebble and cobble-sized particles in the early Emsian of the Ponta Grossa Formation, Paraná Basin (state of Paraná, Brazil). Revista Brasileira de Geociências, 40, 2010, p. 236-241.

GRAHN, Yngve; MENDLOWICZ MAULLER, Paula; BREUER, Pierre; BOSETTI, Elvio Pinto; BERGAMASCHI, Sérgio; PEREIRA, Egberto. The Furnas/Ponta Grossa contact and the age of the lowermost PontaGrossa Formation in the Apucarana Sub-basin (Paraná Basin, Brazil): integrated palynological age determination. Revista Brasileira de Paleontologia, 13, 2010, p. 89-102.

GRAHN, Yngve; MENDLOWICZ MAULLER, Paula; BERGAMASCHI, Sérgio; BOSETTI, Elvio Pinto. Palynology and sequence stratigraphy of three Devonian rock units in the Apucarana Sub-basin (Paraná Basin, south Brazil): Additional data and correlation. Review of Paleobotany and Palynology, v. 198, 2013, p. 27-44.

GRAHN, Yngve; BOSETTI, Elvio Pinto; HORODYSKI, Rodrigo Scalise. Observações sobre as idades dos fósseis descritos por Clarke 1913. Revista Terr@ Plural. Neste volume.

HOLLAND, Steven. The stratigraphic distribution of fossils. Palaeobiology, v.21, 1995, p. 92-109.

HOLZ, Michael; SIMÕES, Marcelo Guimarães. Elementos fundamentais de Tafonomia. Porto Alegre, EDUFRGS, 2002.

HOLZ, Michael; BERTONI-MACHADO, Cristina; SIMÕES, Marcelo Guimarães. A Estratigrafia de seqüências e o registro fóssil. In: Carvalho, Ismar de Souza. (Org.). Paleontologia - conceitos e métodos. 3ed.Rio de Janeiro: Interciência, v. 1, p. 111-137, 2010.

HORODYSKI, Rodrigo Scalise; BOSETTI, Elvio Pinto; MYSZYNSKY JUNIOR, Lucinei José. Tafonomia de alta resolução do afloramento do campus UEPG, sucessão devoniana, sub-bacia de Apucarana, Bacia do Paraná, Brasil. XV ENCONTRO ANUAL DE INICIAÇÃO CIENTÍFICA E VI ENCONTRO DE PESQUISA DA UEPG, Ponta Grossa. 2006, CD-Rom, vol. 1.

KIDWELL, Susan; BOSENCE, Daniel. Taphonomy and Time-Averaging of Marine Shelly Faunas. In: ALLISON, Peter \& BRIGGS, Derek (eds) Taphonomy: Releasing the data locked in the fossil record, Plenum Press, New York and London, 1991, p. 116-188.

KOTZIAN, Carla Bender. Estudo sistemático e morfo-funcional de bivalves (Mollusca) das formações Vila Maria (Siluriano) e Ponta Grossa (Devoniano), Bacia do Paraná, Brasil: Interpretação do regime hidrodinâmico - sedimentar. 1995. Tese (Doutorado em Geociências). Programa de Pós-Graduação em Geociências, UFRGS, Porto Alegre-RS.

KOTZIAN, Carla Bender; SIMÕES, Marcello Guimarães. Edmondia (?) brasiliensis (Clarke, 1913) Nov. Comb. (Bivalvia, Edmondiidae): A new classification and its evolutionary and paleoenvironmental significance. In: CONGRESSO BRASILEIRO DE PALEONTOLOGIA, 15, 1997. Boletim de Resumos.. São Pedro, SP. p. 64.

MARTIN, Ronald. Taphonomy: A process approach. Cambridge: Cambridge University Press. 1999.

MENDLOWICZ MAULLER, Paula; GRAHN, Yngve; MACHADO CARDOSO, Tereza Regina. Palynostratigraphy from the Lower Devonian of the Paraná Basin, south Brazil, and a revision of contemporary chitinozoan biozones from western Gondwana. Stratigraphy, 2009.

MELO, José Henrique Gonçalves. The Malvinokaffric Realm in the Devonian of Brazil. In: McMILLAN, Jack; EMBRY, Ashton; GLASS, Donald (eds.) Devonian of the World. Canadian Society of Petroleum 
Geologists, Proceedings of the $2^{\text {nd }}$ International Symposium on the Devonian System. Calgary, C.S.P.G, Memoir, 14, 1, 1988. p. 667-703.

MENDLOWICZ-MAULLER, Paula; GRAHN, Yngve; CARDOSO, Tereza Regina Machado. Palynostratigraphy from the Lower Devonian of the Paraná Basin, south Brazil, and a revision of contemporary chitinozoan biozones from western Gondwana. Stratigraphy, v. 6, 2009, p. 313-332.

MERGL, Michal. Discinid brachiopod life assemblages: Fossil and extant. Bulletin of Geosciences. 85, 2, 2010, p. 27-38.

MERGL, Michal; MASSA, Dominique. A new giant discinoid brachiopod from the Lower Devonian of Algeria. Acta Palaeontologica Polonica. 50, 2, 2005, p. 397-402.

MILANI, Edison José; MELO, José Henrique Gonçalves; SOUZA, Paulo Alves; FERNANDES, Luiz Alberto; FRANÇA, Almério Barros. Bacia do Paraná. Boletim de Geociências da Petrobrás, n. 15, 2007, p. 265-287.

MYSZYNSKI, Lucinei José. Inserção do afloramento Curva II no contexto tafonômico e estratigráfico da Sequência Neopraguiana-Eoemsiana: interpretação paleoambiental do setor nordeste do sítio urbano de Ponta Grossa, Paraná, Brasil. 2012. Dissertação (Mestrado em Gestão do Território) Programa de PósGraduação em Geografia, UEPG.

NETTO, Renata Guimarães; TOGNOLI, Francisco Manoel Wohnrath; GANDINI, Rosana; LIMA, João Henrique Dobler; GIBERT, Jordi Maria de. Ichnology of the phanerozoic deposits of southern Brazil: sinthetic review. In: NETTO, Renata Guimarães; CARMONA, Noelia Beatriz; TOGNOLI, Francisco Manoel Wohnrath (orgs). Ichnology of Latin America: Selected Papers. Monografias da Sociedade Brasileira de Paleontologia, 2012.

POPP, José Henrique; BARCELLOS-POPP Marlene Teresinha. Análise estratigráfica da sequência devoniana da Bacia do Paraná (Brasil). Revista Brasileira de Geociências, 16, 1986, p. 187-194.

REINECK, Hans-Eric. Parameter von schichtung und bioturbation. Geologische Rundschau, v. 56, 1967.

RODRIGUES, Sabrina Coelho. Tafonomia comparada dos conulatae Collins, Formação Ponta Grossa, Devoniano (Lochkoviano-Frasniano) Bacia do Paraná: Implicações paleoautoecológicas e paleoambientais. 2002. Dissertação (Mestrado em Geociências). Instituto de Geociências, Curso de Pós-Graduação em Geologia Sedimentar, Universidade de São Paulo, São Paulo.

RODRIGUES, Maria Antonieta da Conceição; SOARES, Hilda Leonor Cuevas de Azevedo; BERGAMASCHI, Sérgio. Horizontes de Mortalidade em Massa de Tentaculita na Formação Ponta Grossa, Bacia do Paraná. In: MELO, José Henrique Gonçalves; TERRA, G.J.S. (eds.), Correlação de Sequências Paleozóicas SulAmericanas. Ciência - Técnica - Petróleo. Seção: Exploração de Petróleo v. 20, 2001. p. 73-79.

SANDFORD, Andrew. Homalonotid trilobites from the Silurian and Lower Devonian of south-eastern Australia and New Zealand (Arthropoda: Trilobita: Homalonotidae). Memoirs of Museum Victoria, v. 62, n. 1, 2005, p. 1-66.

SCHEFFLER, Sandro Marcelo. Crinoides e Blastoides do Devoniano brasileiro. 2010. Tese (Doutorado em Geologia). Programa de Pós-Graduação em Geologia, UFRJ, Rio de Janeiro-RJ.

SCHINDLER, Eberhard. Tentaculitoids - An enigmatic group of Paleozoic fossils: Talent, John (ed) Earth and Life, Springer, 2012, p. 479-490.

SIMÕES, Marcello Guimarães; KOWALEWSKI, Michal; TORELLO, Fernanda de Freitas; GHILARDI, Renato Pirani. Devonian and Permian benthic marine invertebrates preserved in life position: taphonomic feedback in a Paleozoic epeiric sea. XVI CONGRESSO BRASILEIRO DE PALEONTOLOGIA, 1999, Crato, CE, Boletim de Resumos, p.109-110.

SIMÕES, Marcello Guimarães; GHILARDI, Renato Pirani. Protocolo tafonomico/paleoautoecológico como ferramenta nas análises paleossinecológicas de invertebrados: exemplos de aplicação em concentrações fossilíferas do paleozóico da Bacia do Paraná, Brasil. Pesquisas em Geociências, n. 27, 2000, p. 3-13.

SIMÕES, Marcello Guimarães; RODRIGUES, Sabrina Coelho; LEME, Juliana de Moraes; ITEN, Heyo Van. Some Middle Paleozoic Conulariids (Cnidaria) as Possible Examples of Taphonomic Artifacts. Journal of Taphonomy, v. 1, n. 3, 2003, p.165-186. 
SIMÕES, Marcello Guimarães; SOARES, Sabrina Pereira; BOSETTI, Elvio Pinto; HOLZ, Michael; LEME, Juliana de Moraes; RODRIGUES, Sabrina Coelho. Sequence stratigraphy and taphonomic data as indicators of narrow water depth range for homalonotid trilobites (phacopida) in the Devonian of Paraná Basin, Brazil. IX CONGRESSO DE PALEONTOLOGÍA Y BIOESTRATIGRAFÍA, 2006, Córdoba. Resúmenes: Academia Nacional de Ciências, p. 268.

SIMÕES, Marcello Guimarães; LEME, Juliana de Moraes; SOARES, Sabrina Pereira. Systematics, Taphonomy, and Paleoecology of Homalnotid Trilobites (Phacopida) from the Ponta Grossa Formation (Devonian), Paraná Basin, Brazil. Revista Brasileira de Paleontologia vol. 12, 2009, p. 27-42.

SIMÕES, Marcello Guimarães; RODRIGUES, S.C.; BERTONI-MACHADO, Cristina; HOLZ, Michael. Tafonomia: Processos e Ambientes de Fossilização. In: Carvalho, I.S.. (Org.). Paleontologia. Rio de Janeiro, RJ: Interciências, 2010, v. 1, p. 19-52.

SOARES, Sabrina Pereira. Sistemática, Tafonomia e Paleoecologia de Trilobita, Phacopida (Homalonotidae, Calmoniidae), Formação Ponta Grossa (Devoniano), Sub-bacia de Apucarana, Estado do Paraná, Brasil. 2007. Dissertação (Mestrado em Geociências). Instituto de Geociências, Curso de PósGraduação em Geologia Sedimentar, Universidade de São Paulo, São Paulo.

SPEYER, Stephen; BRETT, Carlton. Trilobite taphonomy and Middle Devonian taphofacies: Palaios, v. 1, p. 312-327, 1986.

SPEYER, Stephen; BRETT, Carlton. Taphofacies models for epeiric sea environments: Middle Paleozoic examples. Palaeogeography, Palaeoclimatology and Palaeoecology, vol. 63, 1988, p. 222-262.

SÜDKAMP, Wouter. Discovered of soft parts of a fossil brachiopod in the "Hunrsücksciefer" (Lower Devonian, Germany). Paläontologische Zeitschrift. 71, 1-2, 1997, p. $91-95$.

UCHMAN, Alfred. Taxonomy and palaeoecology of flysch trace fossils: the Marnoso-arenacea Formation and associated facies (Miocene, Northern Apennines, Italy) Beringeria, 15, 1995.

VAN ITEN, Heyo. Anatomy, patterns of occurrence, and nature of the conulariid schott. Palaeontology, v. 34, 1991, p. 939-954.

VAN ITEN, Heyo; MUIR, Lucy, A.; BOTTING, Joseph, P.; ZHANG, Y.D.; LIN, J.P. Conulariids and Sphenothallus (Cnidaria, Medusozoa) from the Tonggao Formation (Lower Ordovician, China). Bulletin of Geosciences, vol. 88, 4, 2013, p. 713-722.

WALKER, Roger; JAMES, Noel. Facies Models: response to sea level change. Geological Association of Canada, 1992.

WALKER, Roger; PLINT, Guy. Wave- and storm-dominated shallow marine systems. In: Walker, Roger; James, Noel (eds) Facies Models - response to sea level change. Geological Association of Canada, p 219238, 1992.

WILLIAMS, Alwyn.; CARLSON, Sandra; BRUNTON, Howard; HOLMER, Lars; POPOV, Leonid; MERGL, Michal; LAURIE, John; BASSETT, Michael; COCKS, Robin; RONG, Jia-Yu; LAZAREV, Stanislas; GRANT, Richard; RACHEBOEUF, Patrick; JIN, Yu-Gan.; WARDLAW, Bruce; HARPER, David; WRIGHT Anthony. Linguliformea, Craniiformea, Rhynchonelliformea: Treatise on Invertebrate Paleontology, Part $\mathrm{H}$ Brachiopoda (revised), v. 2-3, p. 1-919, 2000.

WILLIAMS, Alwyn; BRUNTON, Howard; CARLSON Sandra; CARTER, John; CURRY, Gordon; CUSACK, Maggie; DAGYS, Algirdas; GOURVENNEC, Rémy; HOU, Hongfei; JIN, Yu-Gan; JOHNSON, Jess; LEE, Daphne; MACKINNON, David; RACHEBOEUF, Patrick; SMIRNOVA, Tat'jana Nikolaevna; SUN, DongLi. Rhynchonelliformea: Treatise on Invertebrate Paleontology, Brachiopoda, Part H, v. 5, p. 1689-2320, 2006.

WITTMER, Jacalyn; MILLER, Arnold. Dissecting the global diversity trajectory of an enigmatic group: The paleogeographic history of tentaculitoids: Palaeogeography, Palaeoclimatology, Palaeoecology, v. 312, 2011, p. 54-65.

ZABINI, Carolina. Lingulídeos da sucessão devoniana da Bacia do Paraná, região dos Campos Gerais, Brasil: revisão de conceitos biológicos-ecológicos e análise tafonômica básica. 2007. Dissertação (Mestrado em Geociências). Universidade Federal do Rio Grande do Sul, Porto Alegre. 
ZABINI, Carolina. Integração da tafonomia e estratigrafia de sequências no estudo dos lingulídeos da sucessão devoniana da Bacia do Paraná. 2011. Tese (Doutorado em Geociências) - Instituto de Geociências, Programa de Pós-Graduação em Geociências, UFRGS.

ZABINI, Carolina; BOSETTI, Elvio, Pinto. Paleoambientes revelados: Lingulídeos como paleoindicadores em mares Paleozoicos. In: CARVALHO, Ismar de Souza; SRIVASTAVA, Narendra, STROHSCHOEN JR, Oscar; LANA, Cecília Cunha (eds). Paleontologia: Cenários da Vida, Interciência, vol. 4, 2011, p. 287-297.

ZABINI, Carolina; COMNISKEY, Jeanninny Carla. John Mason Clarke e os lingulídeos (ordem: lingulida) dos estratos devonianos da Bacia do Paraná, estado do Paraná, Brasil: estado da arte. Revista Terr@ Plural. Neste volume.

ZABINI, Carolina; BOSETTI, Elvio Pinto; HOLZ, Michael. Taphonomy and taphofacies analysis of lingulid brachiopods from Devonian sequences of the Paraná Basin, Brazil. Palaeogeography, Palaeoclimatology, Palaeoecology, v. 292, 2010, p. 44-56.

Recebido em 30/10/2013

Aceito para publicação em 02/12/2013 